\title{
Meta Grosman: A Comprehensive Bibliography
}

\section{A Note on the Presentation of Publications}

To make Professor Meta Grosman's research and publications more easily accessible for use by scholars interested in the different fields of her studies, her publications have been categorized on the basis of her main research interest into four separate groups according to the predominant subject/topic of the individual publications:

1. Anglo-american literature and literary theory with intercultural and translational studies

2. Literary criticism

3. Didactics of language and literature

4. Reading and literacy

At this point we should draw the readers' attention to the fact that her great interest in, and indeed preoccupation with, reader response and reading processes run through her studies in different areas.

Entries within each of the group listed above have been arranged chronologically; within a single year they appear in alphabetical order.

\section{ANGLO-AMERICAN LITERATURE AND LITERARY THEORY WITH INTERCULTURAL AND TRANSLATIONAL STUDIES}

\section{A. MONOGRAPHS}

1970

Odnos med bralcem in besedno umetnino v luči angleške literarne kritike: Doctoral dissertation. Ljubljana [M. Grosman], 1970, 395 pp. 1974

Odnos med bralcem in besedno umetnino v luči angleške literarne kritike: (1921-1961): izvlecek iz doktorske disertacije $=$ The relation between the reader and the literary work of art in British criticism (1921-1961): abstract of the doctoral dissertation. Ljubljana, Filozofska fakulteta, 1974, 68 pp.

1981 1984

English Novel 1830-1920. First printing. Ljubljana, Filozofska fakulteta, 1981. pp. IX, 324.

English Novel 1830-1920. Second printing. Ljubljana, Filozofska fakulteta, 1984. pp. IX, 324. 1989

Angleški roman: 1830-1920. Third printing, with revisions. Ljubljana, Filozofska fakulteta, Oddelek za germanske jezike in književnosti, 1989. pp. III, 203. 2004

Knjižernost v medkulturnem položaju. Ljubljana, Znanstveni inštitut Filozofske fakultete, 2004, 223 pp. (Razprave Filozofske fakultete series) 


\section{B. STUDIES AND ARTICLES}

1961

Kriza ameriške literature. Naši razgledi 10 (1961), no. 15 (230), p. 375. 1964

Problem vrednotenja v sodobni angleški literarni teoriji in kritiki. Problemi 2 (1964), no. 13, pp. 17-29.

Vprašanje dveh kultur. Problemi 2 (1964), no. 16/17, pp. 369-83. 1969

Scrutiny's Reviews of I. A. Richards' Works. Acta neophilologica 2 (1969), pp. 45-51. 1974

Branje pesmi v tujem jeziku. Jezik in slovstvo 20 (1974/1975), no. 2/3, pp. 60-66. 1977

T. S. Eliot on the Reader and Poetry. Acta neophilologica 10 (1977), pp. 3-40. 1982

The Literary Criticism of Denys Wyatt Harding. Acta neophilologica 15 (1982), pp. 63-95. 1983

Patrick White's Voss: An Attempt at Interpretation. In M. Jurak (ed.), Australian Papers:

Yugoslavia, Europe and Australia. Ljubljana, Filozofska fakulteta, 1983, pp. 263-68. 1985

Denys Wyatt Harding on Entertainment and on Reading. Acta neophilologica 18 (1985), pp. 6997.

Novi pogledi na medkulturno posredovanje leposlovja. Delo 29 (7 May 1987), no. 104, pp. 4-5.

The Pluralistic World of Huckleberry Finn. Acta neophilologica 20 (1987), pp. 53-62.

Shakespearjevi soneti v slovenščini. Slavistična revija 35 (1987), no. 3, pp. 303-20.

Zakaj se književni prevodi in spremne študije starajo. Delo 29 (19 February 1987), no. 41, p. 3, and (26 February 1987), no. 47, pp. 3-4.

1988

The Americanness of American Literature in the European Context. In M. Jurak (ed.), Crosscultural Studies: American, Canadian and European Literatures, 1945-1985: Proceedings of the Symposium on Contemporary Literatures and Cultures of the United States of America and Canada, Bled, Yugoslavia, 9-14 May, 1988. Ljubljana, Filozofska fakulteta, 1988, pp. 345-51.

The Original and Its Translation from the Reader's Perspective. Acta neophilologica 22 (1989), pp. 61-68.

Literary Theory and the Institution of English in USA. In M. Jurak (ed.), Literature, Culture and Ethnicity: Studies on Medieval, Renaissance and Modern Literatures: A Festschrift for Janez Stanonik. Ljubljana, Filozofska fakulteta, Znanstveni inštitut, 1992, pp. 51-59.

Medkulturne funkcije književnega prevajanja: prevod kot sestavni del narodove identitete. Delo 34 (1 October 1992), no. 227, p. 13. 
Relacije književni prevod - izvirnik v luči novejših teorij: kaj beremo, ko imamo pred seboj prevod? Delo 34 (21 May 1992), no. 115, pp. 14-15, [and] (28 May 1992), no. 121, pp. $14-15$.

Treba je vedeti: vsako prevajanje je (tudi) prisvajanje: delovno srečanje slovenskih prevajalcev. Delo 35 (30 September 1992), no. 227, pp. 14-15.

1993

Cross-cultural Awareness through Literary Translation. In C. Dollerup (ed.), Teaching Translation and Interpreting: Insights, Aims, Visions: Abstracts of Papers. Copenhagen, University of Copenhagen, 1993, pp. 8-9.

Nadmoč posameznih jezikov in nevarnosti manipuliranja: je kakovost prevoda nerazrešljiv izziv? Delo 35 (1 July 1993), no. 149, p. 15.

Spoznavati drugačnost drugega le s stališča lastne kulture: jezik in književnost danes. Delo 35 (9 September 1993), no. 209, p. 13.

Cross-cultural Awareness: Focusing on Otherness. In C. Dollerup and A. Lindegaard (eds.), Teaching Translation and Interpreting 2: Insights, Aims, Visions. Amsterdam, Philadelphia, John Benjamins, 1994, pp. 51-57. (Benjamins Translation Library 5)

Status književnega prevoda v ciljni kulturi. In M. Stanovnik, A. Berger, and A. Stanič (eds.), Prevod - posnetek, reprodukcija, interpretacija. Ljubljana, Društvo slovenskih književnih prevajalcev, 1994, pp. 13-17. (Zbornik Društva slovenskih književnih prevajalcev 18) 1995

Multicultural Perspectives on Huckleberry Finn: Including a Look at the Lack of Primary Socialization in Huck's Development. In M. Grosman (ed.), American Literature for NonAmerican Readers: Cross-cultural Perspectives on American Literature. Frankfurt am Main [etc.], Peter Lang, 1995, pp. 33-47.

1996

How to Succeed in a TEMPUS Project: The Ljubljana Centre for Translation and Interpreting. European English Messenger 5 (1996), no. 1, pp. 46-47.

Reader-response Criticism: Interdisciplinary Perspectives. In N. Faria (ed.), Language and Literature Today: Proceedings of the 19th Triennial Congress of the International Federation for Modern Languages and Literatures $=$ Actes du $19 \mathrm{e}$ congrès de la Fédération internationale des langues et littératures modernes, Brasilia 22-30 august 1993. Brasília, Universidade de Brasília, 1996, pp. 842-51.

Književni prevod kot oblika medkulturnega posredovanja leposlovja. In M. Grosman and U. Mozetič (eds.), Književni prevod. Ljubljana, Znanstveni inštitut Filozofske fakultete, 1997, pp. 11-56. (Razprave Filozofske fakultete series)

Književnost v medkulturnem položaju. Razprave. Razred za filološke in literarne vede SAZU 16 (1997), pp. 47-66.

Shakespearjevi soneti in slovenski bralci. In M. Grosman and U. Mozetič (eds.), Književni prevod. Ljubljana, Znanstveni inštitut Filozofske fakultete, 1997, pp. 111-27. (Razprave Filozofske fakultete series) 
Huckleberry Finn v medkulturni perspektivi. Otrok in knjiga. Special issue on "Perspektive v mladinski književnosti”, 1999, pp. 75-87.

Reading Huckleberry Finn across Cultures. Language and Literature 24 (1999). Special issue on "Literature(s) across Culture(s)", pp. 65-78.

Izzivi in področja medkulturne vzgoje. In I. Štrukelj (ed.), Kultura, identiteta in jezik v procesih evropske integracije. Ljubljana, Društvo za uporabno jezikoslovje Slovenije, 2000, pp. 11-22.

Književni prevod med preteklostjo in prihodnostjo. Uporabno jezikoslovje 1999 (published 2000), no. 7/8, pp. 82-99.

Non-Mother Tongue Translation - An Open Challenge. In M. Grosman, M. Kadric, I. Kovačič, and M. Snell-Hornby (eds.), Translation into Non-Mother Tongues: In Professional Practice and Training. Tübingen, Stauffenburg, 2000, pp. 21-33. (Studien zur Translation 8)

Medkulturna zavest proti hibridizaciji (slovenskega) jezika. In A. Vidovič Muha (ed.), Slovenski knjižni jezik - aktualna vprašanja in zgodovinske izkušnje: ob 450-letnici izida prve slovenske knjige: povzetki predavanj $=$ On the occasion of the 450th anniversary of the publication of the first Slovene book: summaries = K 450-letiju izdanija pervoj slovenskoj knigi: rezjume dokladov, Ljubljana, 5.-7. december 2001. Ljubljana, Filozofska fakulteta, Oddelek za slovanske jezike in književnosti, Center za slovenščino kot drugi/tuji jezik, 2001, p. 20. (Obdobja, metode in zvrsti series 20)

American Novels through the Eyes of Slovene Readers. Language and Literature 27 (2002). Special issue on "Intercultural Studies of Literature", pp. 5-26.

Kritika književnega prevoda kot kritika v medkulturnem položaju: $\mathrm{k}$ štiristoletnici Hamleta. In M. Ožbot (ed.), Prevajanje srednjeveških in renesančnih besedil: 27. prevajalski zbornik = Proceedings of the Association of Slovene Literary Translators. Ljubljana, Društvo slovenskih književnih prevajalcev, 2002, pp. 238-49. (Zbornik Društva slovenskih književnih prevajalcev 27) (Obdobni pristop 1)

Literary Translation for the Third Millennium. In T.E. Knight (ed.), Broaching Frontiers, Shattering Boundaries: On Tradition and Culture at the Dawn of the Third Millennium. Bern [etc.], Peter Lang, 2002, pp. 167-78.

Ob štiristoletnici Hamleta: slovenski kritiški zapisi v devetdesetih letih. Vestnik DTJK 36 (2002), no. 1/2, pp. 419-35.

Medkulturna zavest proti hibridizaciji (slovenskega) jezika. In A. Vidovič Muha (ed.), Slovenski knjižni jezik - aktualna vprašanja in zgodovinske izkǔñje: ob 450-letnici izida prve slovenske knjige. Ljubljana, Center za slovenščino kot drugi/tuji jezik pri Oddelku za slovenistiko Filozofske fakultete, 2003, pp. 325-42. (Obdobja 20)

Promoting Intercultural Awareness for Better Understanding and Partnership Education. In A. Riem Natale and R. Albarea (eds.), The Art of Partnership: Essays on Literature, Culture, Language and Education towards a Cooperative Paradigm. Udine, Forum, 2003, pp. 125-32. 
Intercultural Awareness for the European Year of Languages. In S. Bračič, D. Čuden, S. Podgoršek, and V. Pogačnik (eds.), Linguistische Studien im Europäischen Jahr der Sprachen: Akten des 36. Linguistischen Kolloquiums in Ljubljana 2001 = Linguistic studies in the European year of languages: proceedings of the 36th linguistic colloquium, Ljubljana 2001. Frankfurt am Main, Peter Lang, 2004, pp. 231-39. (Linguistik international 13) 2005

Jezikovne in spoznavne komponente medkulturne sporazumevalne zmožnosti. Glas. ZRS Koper 10 (2005), no. 4, pp. 86-87.

Medkulturnost kot izziv sodobnih družb. In V. Mikulič and K. Marc Bratina (eds.), Slovenščina in njeni uporabniki v luči evropske integracije. Koper, Univerza na Primorskem, Znanstvenoraziskovalno središče, Založba Annales, Zgodovinsko društvo za južno Primorsko, 2005, pp. 35-47, 289. (Annales Majora Library)

Multilingual Literacy through Literature. In Literacy without Boundaries: 14. europska konferencija o citanju, Zagreb, 31. srpnja 2005: Book of Abstracts, p. 31.

\section{REVIEWS, PREFACES, FOREWORDS}

1991

Preface. In M. Grosman and U. Mozetič (eds.), Trends in Contemporary British Novel 19401990: A Yugoslav View. Ljubljana, Faculty of Arts and Sciences, English Department, 1991, pp. 5-10.

1995

Introduction: American Literature in Cross-cultural Context. In M. Grosman (ed.), American Literature for Non-American Readers: Cross-cultural Perspectives on American Literature. Frankfurt am Main, Peter Lang, 1995, pp. 7-17.

Predgovor. In M. Grosman and U. Mozetič (eds.), Knjižeuni prevod. Ljubljana, Znanstveni inštitut Filozofske fakultete, 1997, pp. 7-10. (Razprave Filozofske fakultete series) 2001

Predgovor $=$ Foreword. In Nada Šabec and David Limon, Across Cultures: slovensko-britanskoamerisko sporazumevanje = Slovene-British-American Intercultural Communication. Maribor, Obzorja, 2001, pp. 5-10.

2002

Roger Sell: Literature as Communication. The Foundation of Mediating Criticism. John Benjamins Publishing Company, Amsterdam and Philadelphia, 2000 [and] Roger Sell: Mediating Criticism. Literary Education Humanized. John Benjamins Publishing Company, Amsterdam and Philadelphia, 2001. Vestnik DTJK 36 (2002), no. 1/2, pp. 499-502. 2003

Johann Köberl: The Indeterminacy of Beowulf. Lanham, MD, New York, Oxford: University Press of America, 2002. Vestnik DTJK 37 (2003), no. 1/2, pp. 439-40.

Roger D. Sell, ed.: Children's Literature as Communication. Amsterdam and Philadelphia, John Benjamins Publishing Company, 2002, 352 pp. Otrok in knjiga 30 (2003), no. 57, pp. 72-76. 
Meta Grosman: Književnost v medkulturnem položaju. Ljubljana: Znanstveni inštitut Filozofske fakultete, 2004 (Razprave Filozofske fakultete series). 223 pp. In M. Hladnik (ed.), Vloga meje: madžarsko-slovenska razmerja, slovenistika na sosednjih univerzah, zahodnoslovanski študiji, izbor šolskega berila, humanistika in družboslovje v Pomurju. Ljubljana, Slavistično društvo Slovenije, 2005, pp. 240-42. (Zbornik Slavističnega društva Slovenije series 16)

\section{EDITOR}

1991

Trends in Contemporary British Novel 1940-1990: A Yugoslav View. Ljubljana, Faculty of Arts and Sciences, English Department, 1991. 152 pp. (Co-edited with Uroš Mozetič) 1995

American Literature for Non-American Readers: Cross-cultural Perspectives on American Literature. Frankfurt am Main [etc.], Peter Lang, 1995. 215 pp. 1997

Književni prevod. Ljubljana, Znanstveni inštitut Filozofske fakultete, 1997. 127 pp. (Co2000 edited with Uroš Mozetič). (Razprave Filozofske fakultete series)

Translation into Non-Mother Tongues: In Professional Practice and Training. Tübingen, Stauffenburg, 2000. 229 pp. (Co-edited with Mira Kadric, Irena Kovačič, and Mary SnellHornby). (Studien zur Translation 8)

\section{LITERARY CRITICISM}

\section{B. STUDIES AND ARTICLES}

1974

Možnosti opisovanja doživetja besedne umetnine. Sodobnost 22 (1974), no. 12, pp. 963-74. 1978

Umetnostna kritika ni sama sebi namen. Naši razgledi 27 (1978), no. 1 (624), p. 13. 1979

Nevarna razmerja in bralci: literarnoteoretični in sociokulturni vidik. Naši razgledi 28 (1979), no. 8 (655), pp. 228-29.

1981 1986

Vprašanja o estetski vzgoji. Naši razgledi 30 (1981), no. 17 (712), pp. 487-88.

Neznana Lili Novy. Naši razgledi 35 (1986), no. 3 (818), pp. 78-79. 1990

Cena nekdanje zbiralske pridnosti je začela - z računalnikom - padati. Delo 32 (18 January 1990), no. 14, pp. 15-16. 1994

Nekatere slovenske kritiške paradigme - kritike o Kavčičevi Pustoti. In M. Juvan and T. Sajovic 
(eds.), Individualni in generacijski ustvarjalni ritmi v slovenskem jeziku, književnosti in kulturi: ob 10-letnici smrti Marje Boršnikove: mednarodni simpozij v Ljubljani od 24. do 26. junija 1992 pod vodstvom Toneta Pretnarja. Ljubljana, Znanstveni inštitut Filozofske fakultete, 1994, pp. 31-41. (Obdobja 14)

Kritika kot govorno dejanje. Slavistična revija 45 (1997), no. 1/2, pp. 269-92. 2002 2004

Razbiranje in razumevanje mitskih sestavin. Otrok in knjiga 29 (2002), no. 54, pp. 31-38.

Kdo je naslovnik kritike mladinske književnosti? Otrok in knjiga 31 (2004), no. 60, pp. 5-15.

\section{REVIEWS, INTRODUCTIONS}

1997

Od Alice k Butalcem: spremna beseda. In Barbara Simoniti: Nonsens. Ljubljana, Karantanija, 1997, pp. 221-24.

2000

Marko Juvan: Intertekstualnost (Literarni leksikon 45). Ljubljana, DZS, 2000. (ISBN 86-3412084-8). Vestnik DTJK 34 (2000), no. 1/2, p. 523. 2005

Marjan Dović: Sistemske in empirične obravnave literature. Studia Litteraria series. Ljubljana: ZRC SAZU, 2004, 239 pp. [and] Drago Šega: Literarne kritika. Studia Litteraria series. Ljubljana: Založba ZRC SAZU, 2004, 155 pp. Vestnik DTJK 39 (2005), no. 1/2, pp. 34749.

\section{DIDACTICS OF LANGUAGE AND LITERATURE}

\section{A. MONOGRAPHS}

1994

Književnost in jezik za maturo iz angleščine. Ljubljana, Zavod Republike Slovenije za šolstvo in šport, 1994.132 pp. (Co-authored with Saša Benulič). (Matura series) 1996

Angleščina pri maturi: kako se uspešno pripravimo na preizkus znanja iz angleškega jezika. Ljubljana, Republiški izpitni center, 1996. 152 pp. (Co-authored with Ivica Baš, Margaret Dalrymple, Vineta Eržen, Soča Fidler, Majda Grabar, Aleša Juvanc, Smiljana Komar, Cvetka Sokolov, and Rastislav Šuštaršič). (Znanje series) 1997

Angleški jezik: učni načrt: osnutek : gimnazija. Ljubljana, Zavod Republike Slovenije za šolstvo, 1997. 16 pp. (Co-authored with Berta Kogoj, Darinka Šaubah-Kovič, Barbara Gostiša, Melita Kukovec, Marija Potočar, and Nidja Tomažič)

Angleški jezik: učni načrt: osnutek : osnovna šola. Ljubljana, Zavod Republike Slovenije za šolstvo, 1997. 23 pp. (Co-authored with Berta Kogoj, Darinka Šaubah-Kovič, Barbara Gostiša, 
Melita Kukovec, Marija Potočar, and Nidja Tomažič)

Šolska ura s Hamletom. Ljubljana, Zavod Republike Slovenije za šolstvo, 1997. 47 pp. (Coauthored with Veronika Rot Gabrovec)

Jezikovne zmožnosti za maturo iz angleščine. Ljubljana, Zavod Republike Slovenije za šolstvo, 1998. 161 pp. (Co-authored with Saša Benulič, Soča Fidler, Veronika Rot Gabrovec, and Cvetka Sokolov). (Matura series)

Ǔ̌ni načrt: predlog : maj 1998, Angleščina. [Ljubljana]: [n.p.], 1998. 23 pp. (Co-authored with Berta Kogoj, Darinka Šaubah-Kovič, Barbara Gostiša, Melita Kukovec, Marija Potočar, and Nidja Tomažič)

1999

Šolska ura s Salomo Oscarja Wilda. Ljubljana, Zavod Republike Slovenije za šolstvo, 1999. $35 \mathrm{pp}$. 2000

Angleščina - prenovi na pot: zbornik študij o kurikularni prenovi. Ljubljana, Zavod Republike Slovenije za šolstvo, 2000. 253 pp. (Co-authored with Nada Šabec, David Limon, Melita Kukovec, Cvetka Sokolov, Marija Potočar, and Janez Skela)

Šolska ura z besedilom. Ljubljana, Zavod Republike Slovenije za šolstvo, 2000. 68 pp.

Šolska ura z Velikim Gatsbyjem. Ljubljana, Zavod Republike Slovenije za šolstvo, 2000. 104 pp. (Co-authored with Veronika Rot Gabrovec) 2004

Učni načrt: program osnovnošolskega izobraževanja, Angleščina. Ljubljana, Ministrstvo za šolstvo, znanost in šport, Zavod RS za šolstvo, 2004.75 pp. (Co-authored with Berta Kogoj, Darinka Šaubah Kovič, Barbara Gostiša, Melita Kukovec, Marija Potočar, and Nidja Tomažič) 2005

Učni načrt, Izbirni predmet: program osnovnošlskega izobraževanja, Angleščina. Ljubljana, Ministrstvo za šolstvo in šport, Zavod RS za šolstvo, 2005. 44 pp. (Co-authored with Berta Kogoj, Darinka Šaubah Kovič, Barbara Gostiša, Melita Kukovec, Marija Potočar, and Nidja Tomažič)

\section{B. STUDIES AND ARTICLES}

1979

Odlomek pri pouku književnosti. Jezik in slovstvo 25 (1979/1980), no. 1, pp. 14-17.

Pouk literarne interpretacije. Jezik in sloustvo 24 (1978/1979), no. 5/6, pp. 140-49. 1983

Pesem pri pouku tujega jezika: Ode on a Grecian Urn. Vestnik DTJK 17 (1983), no. 2, pp. $4-11$.

1985

Pouk tujega jezika in razvijanje zavesti o jeziku. In N. Bulatovič (ed.), Posvetovanje Mesto in vloga tujih jezikov v naši družbi. Ljubljana, Društvo za tuje jezike in književnosti SRS, 1985, pp. 29-35.

Resna razlaga mora izhajati iz temeljitega poznavanja. Delo 28 (27 March 1986), no. 72, p. 4. 
Oddelek za germanske jezike in književnosti. In V. Melik, N. Šumi, M. Kranjec, and V. Pogačnik (eds.), Zbornik Filozofske fakultete v Ljubljani. Ljubljana, Filozofska fakulteta, 1989, 1990 pp. 189-211.

Profil diplomiranega anglista: želje in realnost. Vestnik DTJK 24 (1990), no. 1/2, pp. 100-105. Znanje tujih jezikov za prihodnost in vključevanje v Evropo. Naši razgledi 39 (1990), no. 10, pp. 293-94.

1991

Književni pouk za učenca. Prosvetni delavec 42 (1991), no. 18, str. 8.

Literature Teaching in Cross-cultural Context. In V. Felbabov (ed.), Teorijske i metodološke osnove nastave stranih jezika i književnosti na filološkim/filozofskim fakultetima u Jugoslaviji: zbornik radova. Novi Sad, Institut za strane jezike i književnosti, Filozofski fakultet, 1991, pp. 75-81.

Pomen tujih jezikov - izziv in odgovornost za učitelja. Vestnik DTJK 25 (1991), no. 1/2, pp. $5-19$.

Še enkrat o študiju germanistike. Prosvetni delavec 42 (1991), no. 11, p. 6.

Študij germanistike: da ali ne. Prosvetni delavec 42 (1991), no. 4, p. 9.

Teaching Three British Novels. In M. Grosman and U. Mozetič (eds.), Trends in Contemporary British Novel 1940-1990: A Yugoslav View. Ljubljana, Faculty of Arts and Sciences, English Department, 1991, pp. 79-97.

Književni pouk ni samo prenos strokovnega znanja. Šolski razgledi 43 (1992), no. 5, p. 6.

Continuing Education Programme of the English Dept., Faculty of Arts, University of Ljubljana. In R. Bolitho and R. Woodham (eds.), Managing Change in Teacher Education: Report of Proceedings. [n.p.:],

The British Council [1993], pp. 64-65.

Medkulturna sestavina pouka tujih jezikov. Vestnik DTJK 27 (1993), no. 1/2, pp. 7-15.

Medkulturni vidiki pouka tujih jezikov. In I. Štrukelj (ed.), Jezik tako in drugače. Ljubljana, Društvo za uporabno jezikoslovje Slovenije, 1993, pp. 190-99.

Načelno "za", v resnici malo ali nič: zakaj je pouk tujih jezikov potreben še na univerzi. Šolski razgledi 44 (1993), no. 1, p. 5.

Ali angleščina res ogroža druge jezike, tudi slovenščino?: razmerje med jeziki. Delo 36 (2 June 1994), no. 126, p. 14.

Cross-cultural Component - A Challenge for EFL. IATEFL Newsletter: Slovenian Branch, (1994), no. 2, pp. 2-4.

Da bi šola ne gojila sovraštva do slovenskega jezika: jezik naš vsakdanji. Delo 36 (22 June 1994), no. 143 , p. 5.

Du ju tič ali miš ingliš? Razgledi (1994), no. 14, pp. 18-21.

The Intercultural Component - A Challenge for ELT. In S. Orel Kos (ed.), Alps-Adriatic Conference on English Language Teaching. Ljubljana, Filozofska fakulteta, Oddelek za germanske 
jezike in književnosti, 1994, pp. 21-22.

Kako do pisne zmožnosti: esej ali pisni sestavek. Šolski razgledi 45 (1994), no. 8, p. 8.

Poučevanje angleščine med preteklostjo in prihodnostjo. Uporabno jezikoslovje (1994), no. 3, pp. 109-19.

Tolažba: učenec je svojo zagato delil s sestavljavci vprašanj. Delo 36 (21 July 1994), no. 167, p. 15. 1995

Trivialno besedilo kot izziv za učitelja. Otrok in knjiga 21 (1994), no. 37, pp. 15-19.

Teaching English Literature in a Cross-cultural Context. In N. Šabec (ed.), Teaching English Language and Literature: zbornik referatov z mednarodnega posvetovanja anglistov v Mariboru, 4.

- 5. marec 1994. Maribor, Pedagoška fakulteta, 1995, pp. 33-42.

Za dijaku prijaznejšo maturo iz angleščine. Vestnik DTJK 29 (1995), no. 1/2, pp. 7-17. 1996

Besedišče. In S. Benulič (ed.), Angleščina pri maturi: kako se uspešno pripravimo na preizkus znanja iz angleškega jezika. Ljubljana, Državni izpitni center, 1996, pp. 144-49. (Znanje series)

For a More Learner-centered Matura. IATEFL Newsletter 4 (1996), no. 1, pp. 13-15.

Književni pouk med preteklostjo in prihodnostjo. Sodobna pedagogika 47 (1996), no. 9/10, pp. 452-68.

Književnost. In S. Benulič (ed.), Angleščina pri maturi: kako se uspešno pripravimo na preizkus znanja iz angleškega jezika. Ljubljana, Državni izpitni center, 1996, pp. 105-20. (Znanje series)

Književnost med elektronskimi in leksikonskimi pristopi: ali postaja pisana beseda mladim zoprna. Delo 38 (18 July 1996), no. 164, pp. 11-12, and (25 July 1996), no. 170, pp. 13-14.

Literature teaching and its goals. LATEFL Newsletter 4 (1996), no. 2, pp. 5-7.

Nov program prevajalskega študija na UL. Vestnik UL 27 (1996), no. 9/10, pp. 2-4.

Nov program univerzitetnega študija prevajanja in tolmačenja na Filozofski fakulteti v Ljubljani. Vestnik DTJK 30 (1996), no. 1/2, pp. 112-14.

Sestavine književnega pouka, ki zavirajo bralno sposobnost: $s$ strokovnega posvetovanja. Delo 38 (12 September 1996), no. 211, p. 15.

Vloga lektorjev pri univerzitetnem študiju tujih jezikov. Vestnik UL 27 (1996), no. 8, pp. 2-4. Vloga lektorjev v univerzitetnem študiju tujih jezikov. Vestnik DTJK 30 (1996), no. 1/2, pp. 306-12.

Teaching English Literature in an Intercultural Context. In M. Grosman (ed.), Approaches to Teaching English in an Intercultural Context. Ljubljana, Faculty of Arts, 1997, pp. 23-45.

Novi učni načrti za angleščino želijo biti pozitiven izziv. Vestnik DTJK 31 (1997), no. 1/2, pp. 7-14.

Osmišljeno samostojno ustvarjanje jezika: predlog novega učnega načrta za angleščino. Šolski razgledi 48 (8 September 1997), no. 13, p. 3.

Vloga učencev z vidika prenove. In K. Destovnik and J. Matovič (eds.), Izobraževanje učteljev ob vstopu v tretje tisočletje: stanje, potrebe, rešitve: zbornik prispevkov, Ljubljana, 6. in 7. junij 1997. Ljubljana, Pedagoška fakulteta, 1997, pp. 289-96. 
The Intercultural Component in Teaching English as a Foreign Language. In M. Grosman, R. de Beaugrande, and B. Seidlhofer (eds.), Language Policy and Language Education in Emerging Nations: Focus on Slovenia and Croatia and with Contributions from Britain, Austria, Spain, and Italy. Stamford (CT), London, Ablex Publishing Corp., 1998, pp. 15-27. (Advances in Discourse Processes 63)

Jezik za danes in jutri. In I. Štrukelj (ed.), Jezik za danes in jutri: zbornik referatov na II. kongresu, Ljubljana, 8. - 10. 10. 1998. Ljubljana, Društvo za uporabno jezikoslovje Slovenije, Inštitut za narodnostna vprašanja, 1998, pp. 46-55.

Matematika ali tuji jezik? Delo 40 (20 April 1998), no. 91, p. 4.

Novi poudarki in sestavine v predlogih učnih načrtov za angleščino. Vestnik DTJK 32 (1998), no. $1 / 2$, pp. 7-16.

Obravnava umetnostnega besedila za učinkovitejše jezikovne zmožnosti v angleščini. Uporabno jezikoslovje (1998), no. 5, pp. 173-88.

Pygmalion = Pigmalion. In M. Grosman (ed.), Jezikovne zmožnosti za maturo iz anglešćine. Ljubljana, Zavod Republike Slovenije za šolstvo, 1998, pp. 17-48. (Matura series)

Tuji jeziki. Razgledi (1998), no. 18, pp. 13-14.

Vprašanja o pouku književnosti. In M. Grosman (ed.), Jezikovne zmožnosti za maturo iz anglešcine. Ljubljana, Zavod Republike Slovenije za šolstvo, 1998, pp. 7-11. (Matura series)

Zakaj je branje leposlovja pomembno za vsakogar. In M. Grosman (ed.), Jezikovne zmožnosti za maturo iz angleščine. Ljubljana, Zavod Republike Slovenije za šolstvo, 1998, pp. 12-16. (Matura series)

1999

Critical Statement in the Classroom. Vestnik DTJK 33 (1999), no. 1/2, pp. 23-32.

Literarna veda kot sestavina književnega pouka. In Z. Jan (ed.), Razpotja slovenske literarne vede. Ljubljana, Zavod Republike Slovenije za šolstvo, 1999, pp. 101-12. (Zbornik Slavističnega društva Slovenije series 9)

Zavest o materinščini pri pouku tujih jezikov = Mother tongue awareness in foreign language teaching. In M. Ivšek (ed.), Materni jezik na pragu 21. stoletja: mednarodni simpozij, Portorož, 2. - 4. decembra 1999. Ljubljana, Zavod Republike Slovenije za šolstvo, 1999, pp. 98-102.

English Studies in Slovenia. In B. Engler and R. Haas (eds.), European English Studies: Contributions towards the History of a Discipline. [Leicester], Published for The European Society for the Study of English by The English Association, cop. (O2000, pp. 201-13. Jezikoslovni opisi in njihova uporabnost v šolstvu. In Z. Jan (ed.), Slovensko jezikoslovje danes in jutri. Ljubljana, Zavod Republike Slovenije za šolstvo, 2000, pp. 219-31. (Zbornik Slavističnega društva Slovenije series 10)

Nekateri novi poudarki v učnih načrtih. In M. Grosman (ed.), Anglešcina - prenovi na pot: zbornik študij o kurikularni prenovi. Ljubljana, Zavod Republike Slovenije za šolstvo, 2000, str. 12-22.

Oddelek za germanske jezike in književnosti. In J. Šumi (ed.), Zbornik Filozofske fakultete $v$ Ljubljani. Ljubljana, Filozofska fakulteta, 2000, pp. 329-39. (Co-authored with Anton Janko) 
Pouk književnosti. In M. Grosman (ed.), Anglešcina - prenovi na pot: zbornik študijo kurikularni prenovi. Ljubljana, Zavod Republike Slovenije za šolstvo, 2000, pp. 22-31.

The Sociocultural Component in the New English Curricula. IATEFL Newsletter 4 (2000), no. 13 , pp. 4-6.

2001

Kritika in pogovor o umetnostnem besedilu. Vestnik DTJK 35 (2001), no. 1/2, pp. 375-84. Tuji jeziki: mesto in vloga. Slovenščina v šoli 6 (2001), no. 1/2, pp. 4-5.

Zavest o materinščini pri pouku tujih jezikov. In M. Ivšek (ed.), Materni jezik na pragu 21. stoletja: zbornik Mednarodnega simpozija Materni jezik na pragu 21. stoletja v Portorožu, 2. decembra 1999. Ljubljana, Zavod Republike Slovenije za šolstvo, 2001, pp. 32-39. 2002

The European Year of Languages (EYL) Calls for Higher Language Awareness. In M. Belak (ed.), Conference Selections. Ljubljana, IATEFL, 2002, pp. 8-18. 2003

Ali je možen književni pouk brez odtujevanja učencev? In M. Jesenšek (ed.), Perspektive slovenistike ob vključevanju v Evropsko zvezo. Ljubljana, Slavistično društvo Slovenije, 2003, pp. 151-56. (Zbornik Slavističnega društva Slovenije series 14)

Jezikovno znanje za delovanje v Evropi. In M. Jesenšek (ed.), Perspektive slovenistike ob vključevanju v Evropsko zvezo. Ljubljana, Slavistično društvo Slovenije, 2003, pp. 32-49. (Zbornik Slavističnega društva Slovenije series 14)

Slovenia: Twelve Years of Possibilities and Challenges. European English Messenger 12 (2003), 2004 no. 2, pp. 62-63.

Ali je književnost pri pouku slovenščne kot tujega jezika lahko zanimiva? Jezik in slovstvo 49 (2004), no. 3/4, pp. 123-32.

Can Literature Teaching Be Functional for Students? ELOPE 1 (2004), no. 1/2, pp. 141-56. Cognitive Development through Literature. In M. Belak and K. Leban (eds.), Conference Selections. LATEFL Slovenia, 10th Annual Conference. Ljubljana, IATEFL, 2004, pp. 78-86.

Cultural Awareness in Curricula and Learning Materials. In G. Zarate (ed.), Cultural Mediation in Language Learning and Teaching. Strasbourg, European Centre for Modern Languages, Council of Europe Publishing, 2004, pp. 59-61.

Jezikovna znanja za uspešno splošno izobrazbo. In M. Ivšek (ed.), Zbornik prispevkov mednarodnega posveta o splošni izobrazbi, Portorož, 16.-17. april 2004. Ljubljana, Zavod Republike Slovenije za šolstvo, 2004, pp. 171-80.

Ali novi učni načrti za slovenščino spodbujajo pismenost? Sodobna pedagogika 56 (2005), special number, pp. 106-19.

Izbor besedil za šolsko branje. In M. Hladnik (ed.), Vloga meje: madžarsko-slovenska razmerja, slovenistika na sosednjih univerzah, zahodnoslovanski študiji, izbor šolskega berila, humanistika in družboslovje v Pomurju. Ljubljana, Slavistično društvo Slovenije, 2005, pp. 138-41. (Zbornik Slavističnega društva Slovenije series 16)

Jezikovna ozaveščenost kot motivator zanimanja za jezik. Jezik in slovstvo 50 (2005), no. 5, pp. 3-19. 
Literature Teaching as a Challenge. In S. Duangsamosorn (ed.), Re-imagining Language and Literature for the 21st Century: Selected Proceedings of the XXII International Congress of FILLM Held at Assumption University, Bangkok, Thailand from 19-23 August 2002. Amsterdam, Rodopi, 2005, pp. 241-55. (Textxet. Studies in Comparative Literature 49)

\section{REVIEWS, FOREWORDS}

1994

IATEFL in ESSE v Sloveniji: International Association of Teachers of English as a Foreign Language in European Society for the Study of English. Vestnik DTJK 28 (1994), no. 1/2, pp. 403-4.

Uvod [to the topical issue of Učenje tujih jezikov]. Uporabno jezikoslovje (1994), no. 3, pp. 5-9. 1996

Dvajseti kongres zveze vseh mednarodnih društev za jezike in književnosti FILLM. Vestnik DTJK 30 (1996), no. 1/2, pp. 302-5.

Language and Literature Today. Proceedings of the XIXth triennial congress of the International federation for modern languages and literatures Universidade de Brasilia, 1996, 1390 pp. Vestnik DTJK 30 (1996), no. 1/2, pp. 322-23.

Introduction - Interculturality as a Context. In Approaches to Teaching English in an Intercultural Context. Ljubljana, Faculty of Arts, 1997, pp. 2-8.

Predgovor. In M. Grosman et al. (eds.), Predmetni izpitni katalog za maturo 1999, Angleški jezik, [published] 1997, pp. 5-6.

1998

Predgovor. In M. Grosman (ed.), Jezikovne zmožnosti za maturo iz angleščine. Ljubljana, Zavod Republike Slovenije za šolstvo, 1998, pp. 4-6. (Matura series) 1999

Language Policy and Language Education in Emerging Nations. Novice iz Epicentra, 1999, no. 2 , p. 6.

$\mathrm{Na}$ pragu besedila: učbenik za slovenski jezik v 1 . letniku gimnazij, strokovnih in tehničnih šol. Priročnik za učitelja in delovni zvezek. Založba Rokus, Ljubljana, september 1999. Vestnik DTJK 33 (1999), no. 1/2, pp. 527-28.

Challenges of Literary Texts in the Foreign Language Classroom. Ured. Lothar Bredella in Werner Delanoy. Založba Gunter Narr Verlag Tübingen, 1996 (ISBN 3-8233-5283-0) in Interkultureller Fremdsprachenunterricht. Ured. Lothar Bredella in Werner Delanoy. Založba Gunter Narr Verlag, Tübingen, 1999 (ISBN 3-8233-5301-2). Vestnik DTJK 34 (2000), no. 1/2, pp. 517-18.

Na pragu besedila: učbenik za slovenski jezik v 2. letniku gimnazij, strokovnih in tehničnih šol. Priročnik za učitelje in delovni zvezek. Založba Rokus, Ljubljana, 2000. Vestnik DTJK 34 (2000), no. 1/2, pp. 521-22.

Predgovor: pouk angleščine z vidika prenove. In Grosman, Meta (ed.), Angleščina - prenovi na pot: zbornik študij o kurikularni prenovi. Ljubljana, Zavod Republike Slovenije za šolstvo, 2000, 
pp. 7-11.

Research into Teaching English to Young Learners. Ured. Jayne Moon in Marianne Nikolov. Pecs, University Press, 2000. (ISBN 963-641-568-4). Vestnik DTJK 34 (2000), no. 1/2, pp. 519-20.

2001

Na pragu besedila: učbenik za slovenski jezik v 3. letniku gimnazij, strokovnih in tehniških šol. Priročnik za učitelja in Delovni zvezek, video kaseta. Založba Rokus, Ljubljana, 2001. Vestnik DTJK 35 (2001), no. 1/2, pp. 493-94.

Nova slovnica za učenje slovenščine za tujce: Peter Herrity: Slovene - a comprehensive grammar. Routledge Grammars. Routledge: London in New York, 2000. Vestnik DTJK 35 (2001), no. $1 / 2$, pp. $495-96$.

2002

$\mathrm{Na}$ pragu besedila: učbenik za slovenski jezik v 4. letniku gimnazij, strokovnih in tehničnih šol. Priročnik za učitelje ter delovni zvezek. Založba Rokus, Ljubljana, september 2002. Vestnik DTJK 36 (2002), no. 1/2, pp. 497-98.

\section{EDITOR}

1994

Učenje tujih jezikov. Uporabno jezikoslovje: tematska številka, 1994, no. 3. Ljubljana, Društvo za uporabno jezikoslovje, 1994. $191 \mathrm{pp}$.

1997

Approaches to Teaching English in an Intercultural Context. Ljubljana, Faculty of Arts, $1997.85 \mathrm{pp}$.

1998

Angleški jezik in književnost: študijski program. Ljubljana: Filozofska fakulteta, Oddelek za anglistiko in amerikanistiko, 1998. 76 pp. (Co-edited with Rastislav Šuštaršič)

Language Policy and Language Education in Emerging Nations: Focus on Slovenia and Croatia and with Contributions from Britain, Austria, Spain, and Italy. Stamford (CT), London, Ablex Publishing Corp., 1998. XV, 299 pp. (Co-edited with Robert de Beaugrande and Barbara Seidlhofer). (Advances in Discourse Processes 63)

\section{READING AND LITERACY}

\section{A. MONOGRAPHS}

1989

Bralec in književnost. Ljubljana, Državna založba Slovenije, 1989. 109 pp. 2004

Zagovor branja: bralec in književnost v 21. stoletju. Ljubljana, Sophia, 2004. VI, 310 pp. 2006

(Beseda series 4)

Razsežnosti branja: za boljšo bralno pismenost. Ljubljana, Karantanija, 2006. 296 pp. 


\section{B. STUDIES AND ARTICLES}

1966

1971

"Bralec" in literatura. Problemi 4 (1966), no. 39, pp. 325-40.

Možnosti razločevanja med leposlovnim jezikom in drugimi rabami jezika. Jezik in slovstvo 17 (1971/72), no. 1/2, pp. 1-10.

Bralna kultura ali bralna sposobnost. Delo 32 (21 August 1980), no. 195, p. 14. 1986

Kako do bolj pretanjene bralne sposobnosti: osvetlitev nekaterih značilnosti nove raziskave Knjiga in bralci III. Delo 28 (27 February 1986), no. 48, p. 7, and (6 March 1986), no. 54, pp. 8-9.

Nekateri učinki kiča na otroka. Otrok in knjiga 15 (1987), no. 25, pp. 25-35.

Pouk bralne sposobnosti. Jezik in sloustvo 32 (1986/87), no. 5, pp. 133-41, and no. 6, pp. $188-96$.

Kako beremo leposlovje: posebna oblika institucionaliziranega sporočanja. Delo 30 (14 January 1988), no. 10, pp. 7-8, and (21 January 1988), no. 16, pp. 7-8, and (28 January 1988), no. 22, pp. 7-9.

Kako čitamo beletristiku. Quorum 4 (1988), no. 4 (21), pp. 144-61. 1990

Doživetje besedne umetnine in ubesedovanje. Koroški fužinar 40 (1990), no. 4, pp. 22-24. 1991

Branje. Šolska knjižnica 1 (1991), no. 1, pp. 2-4. 1992

Branje - možnost ustvarjalne porabe prostega časa. Informacije ZPMS, 1992, no. 1, pp. 2125.

Skrb za sistematično vzgojo bralne sposobnosti in pismenosti: kaj in kako bomo Slovenci brali. Delo 34 (27 February 1992), no. 47, pp. 13-14. 1996

Is Literature for Children Still Necessary? In P. Neubauer (ed.), Children in Literature - Children's Literature: Acts of the XXth FILLM Congress 1996, Regensburg, Germany. Frankfurt am Main [etc.], Peter Lang, 2002, pp. 23-34.

Jezikovne zmožnosti in bralna sposobnost. Vestnik DTJK 30 (1996), no. 1/2, pp. 7-12. 1997

Branje kot dejavna jezikovna raba. In M. Grosman (ed.), Poukbranja z vidika prenove. Ljubljana, Zavod Republike Slovenije za šolstvo, 1997, pp. 15-37.

Sestavine književnega pouka, ki zavirajo razvoj bralne sposobnosti. In M. Grosman (ed.), Pouk branja z vidika prenove. Ljubljana, Zavod Republike Slovenije za šolstvo, 1997, pp. 39-50. 1998

Risanka ali pravljica. Otrok in knjiga 25 (1998), no. 46, pp. 52-61. 
Zakaj je bralna sposobnost skrb nas vseh. In S. Novljan (ed.), Branje - skrb vseh. Ljubljana, Bralno društvo Slovenije, 1998, pp. 9-25.

1999

Razmišljanje Mete Grosman. Novice iz Epicentra (1999), special issue <English reading badge>, pp. 1-2.

Besedo ima predsednica društva: BDS - za boljšo bralno zmožnost. Glas Bralnega društva Slovenije 1 (2000), no. 1, pp. 1-3.

Od spontanega do nadgrajenega in reflektiranega branja. In M. Ivšek (ed.), Bralna sposobnost ima neomejene možnosti razvoja: zbornik Bralnega drustva Slovenije, Postojna, november 1999. Ljubljana, Zavod Republike Slovenije za šolstvo, 2000, pp. 11-33.

Pomanjkljiva pismenost - posledica šolskega odnosa do jezika. In M. Velikonja (ed.), Pismenost, participacija in družba znanja. Ljubljana, Andragoški center Republike Slovenije, 2000, pp. 158-61.

Zakaj brati?: vprašanje, ki terja vedno nove odgovore. In I. Saksida (ed.), Bralna značka v tretjem tisočletju: zbornik ob 40-letnici bralne značke. Ljubljana, Rokus, 2000, pp. 21-26.

Evropsko leto jezikov 2001 in pismenost. Glas Bralnega društva Slovenije 2 (2001), no. 2, pp. $1-4$.

Nekatere posebnosti branja leposlovja. In M. Ivšek (ed.), Različne vrste branja terjajo razvijanje različnih bralnih strategij: zbornik Bralnega drusttva Slovenije. Ljubljana, Zavod Republike Slovenije za šolstvo, 2001, pp. 13-23.

Otrokova bralna uspešnost se začne doma. Ciciban za starše (2001), no. 9, pp. 16-17.

Zakaj je bralna zmožnost osnova šolske in poznejše uspešnosti. Ciciban za starše (2001), no. 10, pp. 8-9.

2002

Za uspešno svetovanje moramo poznati branje. In E. Stružnik et al. (eds.), Učenje in poučevanje s knjižnico v osnovni šoli. Ljubljana, Zavod Republike Slovenije za šolstvo, 2002, pp. 51-61. (Modeli poučevanja in učenja, Knjižnična dejavnost series)

8. september - mednarodni dan pismenosti. In M. Ivšek (ed.), Pogovor o prebranem besedilu: zbornik Bralnega drustva Slovenije, Ljubljana, 8. september 2003. Ljubljana, Zavod Republike Slovenije za šolstvo, 2003, pp. 8-9.

Leposlovno branje in pouk po meri današnjih mladih in njihovih potreb. Otrok in knjiga 30 (2003), no. 57, pp. 19-29.

Pogovor o prebranem besedilu: posvetovanje Bralnega društva Slovenije 2003. Otrok in knjiga 30 (2003), no. 57, pp. 69-71.

Pogovor o umetnostnem besedilu. In M. Ivšek (ed.), Pogovor o prebranem besedilu: zbornik Bralnega drustva Slovenije, Ljubljana, 8. september 2003. Ljubljana, Zavod Republike Slovenije za šolstvo, 2003, pp. 73-90.

Pomen branja za posameznika in širšo družbo. In M. Blatnik Mohar (ed.), Beremo skupaj: priročnik za spodbujanje branja. Ljubljana, Mladinska knjiga, 2003, pp. 10-11. 
Bralec in književnost v 21. stoletju: odlomek iz knjige Mete Grosman Zagovor branja. Delo 46 (3 November 2004), no. 255, p. 14.

Novi odgojni potencijali suvremene književnosti za djecu u 21. stoljeću. In R. Javor (ed.), Stručni skup "Književnost i odgoj”, Zagreb, 29. travanj 2003. Zagreb, Knjižnice grada Zagreba, 2004, pp. 26-37.

Obdani z besedami. Šolski razgledi 55 (2004), no. 18, p. 1. 2005

Poti do višje pismenosti terjajo sistematično prizadevanje. In J. Vintar (ed.), Kako naj šola razvija branje in sirrso pismenost: zbornik Bralnega društva Slovenije, Ljubljana, 8. september 2005. Ljubljana, Zavod Republike Slovenije za šolstvo, 2005, pp. 5-14.

Znanja in prepričanja slovenskih učiteljev o bralni pismenosti. Vzgoja in izobraževanje 36 ( 2005), no. 2/3, pp. 39-49. (Co-authored with Sonja Pečjak)

Znanja za uspešen pouk pismenosti. In J. Vintar (ed.), Kako naj šola razvija branje in širšo pismenost: zbornik Bralnega drustva Slovenije, Ljubljana, 8. september 2005. Ljubljana, Zavod Republike Slovenije za šolstvo, 2005, pp. 15-35.

2006

Vzgojni izzivi šolske knjižnice in znanja za njihovo uresničevanje. Šolska knjižnica 16 (2006), no. 2, pp. 54-62.

2007

Ali potrebujemo uspešnejšo literarno socializacijo? In S. Rugelj (ed.), Slovenska knjiga včeraj in jutri. Ljubljana, Umco, 2007, pp. 143-60. (Premiera book series 62. Knjige o knjigah).

\section{REVIEWS, FOREWORDS}

1994

Štrukelj, I. (ed.) (1993) Jezik tako in drugače, Ljubljana, Društvo za uporabno jezikoslovje Slovenije, str. 456. Uporabno jezikoslovje, 1994, no. 2, pp. 137-39. 1998

Pouk branja z vidika prenove: Strokovno posvetovanje Bralnega društva Slovenije 12. in 13. septembra 1996, Ljubljana, Zavod za šolstvo, 1997. In Z. Jan (ed.), Janko Kersnik in njegov čas. Ljubljana, Zavod Republike Slovenije za šolstvo, 1998, pp. 166-68. (Zbornik Slavističnega društva Slovenije series 8)

2000

Paul Kropp: Vzgajanje bralca: naj vaš otok postane bralec za vse življenje. In M. Ivšek (ed.), Bralna sposobnost ima neomejene možnosti razvoja: zbornik Bralnega društva Slovenije, Postojna, november 1999. Ljubljana, Zavod Republike Slovenije za šolstvo, 2000, pp. 282-83. 2001

Uvodna beseda. In M. Ivšek (ed.), Različne vrste branja terjajo razvijanje različnih bralnih strategij: zbornik Bralnega društva Slovenije. Ljubljana, Zavod Republike Slovenije za šolstvo, 2001, pp. 7-12.

Kako naj šola razvija branje in širšo pismenost: Zbornik Bralnega društva Slovenije, uredila Jelka Vintar. Zavod Republike Slovenije za šolstvo, 2005. Otrok in knjiga 32 (2005), no. 64, 
pp. 72-75.

Knjižna kultura 2005. Otrok in knjiga 32 (2005), no. 64, pp. 81-86.

Meta Grosman. Zagovor branja: Bralec in književnost v 21. stoletju. Ljubljana: Sophia, 2004 (Beseda series, 2004, Vol. 4). 310 str. In M. Hladnik (ed.), Vloga meje: madžarsko-slovenska razmerja, slovenistika na sosednjih univerzah, zahodnoslovanski študiji, izbor šolskega berila, humanistika in družboslovje v Pomurju. Ljubljana, Slavistično društvo Slovenije, 2005, pp. 23940. (Zbornik Slavističnega društva Slovenije series 16)

Meta Grosman. Razsežnosti branja: za boljšo bralno pismenost. Ljubljana: Karantanija, 2006, 295 str. In M. Hladnik (ed.), Preseganje meje: izdajanje slovenske leposlovne klasike, slovenistični Zagreb, ilirizem, slovanske literature in slovenska književnost, slovenistična in primerjalna literarna veda, slovenist v razredu, mladinska književnost. Ljubljana, Slavistično društvo Slovenije, 2006, pp. 323-26. (Zbornik Slavističnega društva Slovenije series 17)

\section{EDITOR}

1997

Pouk branja z vidika prenove. Ljubljana, Zavod Republike Slovenije za šolstvo, 1997. 103 pp.

\section{INTERVIEWS WITH AND ARTICLES ON META GROSMAN}

1969

Meta Grosman-Dokler, mag., asistentka pri oddelku za germanske jezike in književnosti. In

Biografije in bibliografije univerzitetnih učiteljev in sodelavcev, Vol. 2. Ljubljana, Univerza, 1969, pp. 91-92.

1979

Dr. lit. zg. znan. Meta Grosman, mag., dipl. germ., asist. za angleško in ameriško književnost.

In Biografije in bibliografije univerzitetnih učiteljev, znanstvenih delavcev in sodelavcev (3 vols.), Vol. 1. Ljubljana, Univerza, 1979, pp. 125-26.

1993

Grosman, Meta. In I. Kreft (ed.), Kdo je kdo za Slovence. Ljubljana, Založba FAGO, 1993, p. 67.

1995

Dr. lit. zg. znan. Meta Grosman, mag., dipl. germ., red. prof. za angleško in ameriško književnost. In Biografije in bibliografije univerzitetnih učiteljev, znanstvenih delavcev in sodelavcev (4 vols.), Vol. 1. Ljubljana, Univerza, 1995, pp. 28-29.

Dr. lit. zg. znan. Meta Grosman, mag., dipl. germ., red. prof. za angleško in ameriško književnost. In Biografije in bibliografije univerzitetnih uciteljev, znanstvenih delavcev in sodelavcev (5 vols.), Vol. 3. Ljubljana, Univerza, 1999, pp. 2213-14.

Grosman, Meta. In Drago Bajt: Slovenski kdo je kdo. Ljubljana, Nova revija, 1999, p. 157.

Po novem šest let angleščine. Delo 41 (29 November 1999), no. 277, p. 10. 
[On the occasion of the transition to the nine-year primary school. Interviewed by Vedrana Grisogono.]

V Shakespearovem znamenju. Mag 5 (1999), no. 45, pp. 72-74.

[Portrait. Interviewed by Vedrana Grisogono.] 2000

Dr. Meta Grosman (Ljubljana, 18. 5. 1936). In Zbornik [Filozofske fakultete]: 1919-1999. Ljubljana, Filozofska fakulteta, 2000, pp. 349-50.

Meta Grosman. LATEFL Newsletter 4 (2000), no. 14/15, pp. 6-7.

[Portrait. Interviewed by Mojca Belak.]

2001

Dr. Meta Grosman (Ljubljana, 18. 5. 1936). In Enciklopedija Slovenije, Vol. 16. Ljubljana, Mladinska knjiga, 2001, p. 73.

The Invasion of Capital and Piebald Illiteracy: An Interview with Dr. Meta Grosman, Department of English and American language and literature of the Philosophy Faculty of the University of Ljubljana. Slovenija 15 (2001), no. 1, pp. 34-37.

[Portrait. Interview conducted by Jasna Snežič.]

Prodor kapitala in lisasta nepismenost: pogovor z dr. Meto Grosman z oddelka za anglistiko in amerikanistiko ljubljanske Filozofske fakultete. Večr 41 (3 February 2001), no. 277, pp. 4243.

[Portrait. Interview conducted by Jasna Snežič.] 2003

Jezik, osnovno orodje moči: $\mathrm{z}$ dr. Meto Grosman o branju in razlogih za našo slabo pismenost. Večer 59 (20 December 2003), no. 294 (180392), p. 41.

[Portrait. Interviewed by Jasna Snežič.]

Pameten človek se pusti prevajati: pogovor z dr. Meto Grosman ob evropskem dnevu jezikov o dilemah prevajanja. Dnevnik 53 (3 October 2003), no. 268, p. 16.

[Interviewed by Ranka Ivelja.]

Profesorja Toporišiča občudujem, da si upa hoditi po cesti. Ona 5 (2003), no. 47, pp. 9-12.

[Portrait. Interviewed by Nika Vistoropski.] 2005

Bomo propadli kot neandertalci?: zagovor branja. Šlski razgledi 56 (2005), no. 3, p. 5. [Interviewed by Mojca Zupan.]

Bi se pustili posiliti z ričetom, če ga ne marate? Večer 62 (11 November 2006), no. 261 (18954), pp. 36-37.

[Portrait. Interviewed by Jasna Snežič.]

Za boljšo bralno pismenost. Delo 48 (6 September 2006), no. 206, p. 16.

[Portrait. Interviewed by Barbara Hanuš.]

Žerjal, Ivan: Oris pomena bralne pismenosti v 21. stoletju za razvijanje jezikovnih zmožnosti ter za spoznavni in osebnostni razvoj. Primorski dnevnik 62 (5 September 2006), no. 208, p. 3.

[Portrait. On the opening lecture delivered by prof. dr. Meta Grosman in Gorizia at the $41^{\text {st }}$ autumn seminar for Slovene teachers in Italy.] 
Ilich, Iztok: Analize, ugotovitve in nasveti za boljšo bralno pismenost: Meta Grosman, ugledna raziskovalka različnih vidikov branja je zbrala razprave in članke, napisane $\mathrm{v}$ zadnjih letih. Primorski dnevnik 63 (12 January 2007), no. 63, p. 12.

[On Meta Grosman’s book Razsežnosti branja (2006).]

Compiled, edited, and translated by Kristina Pegan Vičič and Dušan Gabrovšek 